\title{
Syllable weight and tone in Mara Bantu languages
}

\section{Aunio, Lotta}

John Benjamins

2017

Aunio , L 2017 , Syllable weight and tone in Mara Bantu languages . in P Newman (ed.), Syllable Weight in African Languages . Current Issues in Linguistic Theory, no. 338 , John Benjamins , Amsterdam , pp. 191-214 . https://doi.org/10.1075/cilt.338.12aun

http://hdl.handle.net/10138/308788

https://doi.org/10.1075/cilt.338.12aun

acceptedVersion

Downloaded from Helda, University of Helsinki institutional repository.

This is an electronic reprint of the original article.

This reprint may differ from the original in pagination and typographic detail.

Please cite the original version. 


\section{SYLLABLE WEIGHT AND TONE IN MARA BANTU LANGUAGES}

\section{Lotta Aunio}

\section{Introduction}

The Mara region in Western Tanzania is central in the expansion of the Bantu languages. Some hypotheses regarding the Bantu expansion place early Bantu communities to the west of Lake Victoria as the result of a primary migration from Cameroon (Pakendorf, Bostoen, \& Filippo 2011: 56). Under this scenario, these Bantu communities would have soon spread to the east side of the lake to the present-day Mara region (Nurse 1999: 9). While there have been speakers of Bantu languages in the area for some two thousand years, it has also been inhabited by speakers of Cushitic and Nilotic languages for centuries (Shetler 2007). Nowadays, there are about 20 Bantu language varieties in the area (Hill et al. 2007). Despite close contacts over the centuries, these varieties show a remarkable amount of variation in many areas of the languages (Aunio et al. n.d.). Moreover, the languages have been affected by long-term contact with other language groups in the area, notably the Southern Nilotic Datooga and Eastern Nilotic Maa.

Ikoma-Nata-Isenye (henceforth INI) and Ngoreme, the JE40 Mara Bantu language varieties discussed in this article, show interaction between tones and syllable weight. In these varieties, the Tone Bearing Unit (TBU) is the syllable, and heavy syllables attract $\mathrm{H}$ tones; however, the contexts of this attraction vary from one variety to another. Some more 
northern JE40 languages, Kuria (Marlo, Chacha Mwita, \& Paster 2014) and Simbiti have the mora as the TBU and therefore a rather different system of assigning tones.

In the following I discuss the interaction of syllable weight and tone in Ikoma-NataIsenye (INI) and Ngoreme and demonstrate how tone realizations are affected by syllable weight in different ways in the four varieties. All data cited come from the author's own fieldwork or from SIL databases that have kindly been made available to the author.

\section{Ikoma-Nata-Isenye and Ngoreme}

Two groups of the JE Bantu language are found in the Mara region, the Haya-Jita group (JE20) and the Logooli-Kuria group (JE40). (The codes refer to the Bantu referential classification as set out in Maho (2009). The Haya-Jita group is represented by the JE25 languages Jita, Kwaya, and Ruri. In addition to INI (JE45) and Ngoreme (JE401), there are several other JE40 Bantu languages in the area. These include Zanaki (JE44), Ikizu (JE402), Kabwa (JE405), Kuria (JE43), and Simbiti (JE431).

<Map 1 Mara region languages and dialects (Used by permission, (C) SIL International®)>

Ngoreme is the largest of the varieties discussed here, both geographically and by number of speakers. Ngoreme has about 50,000 speakers, while Ikoma $(19,000)$, Nata $(7,000)$, and Isenye $(8,000)$ have considerably fewer (Muzale \& Rugemalira 2008). Ikoma, Nata, and Isenye have the same identification, which indicates that they are viewed as dialects of the same language (INI). Nevertheless, there are considerable differences in verbal inflection and tonal systems. The term "variety" is used here to refer to the speech of the different groups without arbitrarily classifying them as dialects or separate languages.

The transcription of the language data used in this paper mainly follows the orthography proposals for Ikoma and Ngoreme (SIL 2010; 2011). Deviations from the orthography 
proposals are the use of $\mathbf{y}$ for the velar nasal, $\mathbf{r}$ for the alveolar trill, $\mathbf{f}$ for the alveolar flap, and the symbols $\boldsymbol{\varepsilon}$ and $\mathbf{\rho}$ for the open-mid vowels. Non-distinctive conditioned long vowels are written with double vowels so that their functioning in syllable weight is evident.

\section{Segmental structure of nouns and verbs}

The segmental structure of INI and Ngoreme verbs is typical for Bantu languages of the area (Nurse 2008). The inflectional slots for verbal morphemes are the subject marker slot (SM), the tense/aspect/mood slot (TAM), the object marker slot (OM), and the slot for the final vowel or suffix (FV), as in (1). [The key to abbreviations is provided at the end of the paper.]

(1) Segmental structure of INI and Ngoreme verbs

$(\mathrm{FOC})+(\mathrm{SM})+(\mathrm{NEG})+(\mathrm{TAM})+(\mathrm{OM})+\operatorname{root}(+\mathrm{EXT})+\mathrm{FV}$

In addition, many verbal forms have a nasal preceding the subject marker, but only in the indicative and not, for example, in the relative or negative forms. The nasal has possibly grammaticalized from the copula ni, which marks focus or emphasis on the verb (thus it is indicated as FOC in this paper), but it has become lexicalized in present day INI and Ngoreme (Walker 2013). The verb base can be a verbal root only or a root with verbal derivation suffixes called extensions. The root (with possible extensions), together with the final suffix, forms the stem. When an object marker is added to the stem, the entity is called the macrostem, which is a relevant entity for the assignment of verbal tones in Ikoma and Isenye. In the examples in this paper, the left edge of the macrostem is marked with "[". In the Imperative, only the root and final slot are filled (2) whereas in other verb forms different combinations of the slots are occupied (3). All prefixes with $\mathbf{k}$ are subject to Dahl's Law, a dissimilatory process in which $\mathbf{k}$ is voiced when followed by a voiceless consonant other than h (Hyman 2003: 56). 
(2) Ikoma: raagera!

raager-a

eat-FV

'Eat!'
(3) Ikoma: mbaago[kúrectera

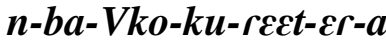

FOC-2.SM-NPST-2.SG.OM-bring-APPL-FV

'they bring/will bring you'

INI and Ngoreme also have a canonical Bantu noun structure, as in (4) and (5):

(4) Canonical noun in INI and Ngoreme

V- $\quad$ CV- stem

AUG- NPX- $\quad$ stem

(5) Ikoma: o-mu-saaní

1.AUG-1.NPX-friend

'friend' a-ba-saaní

2.AUG-2.NPX-friend

'friends'

Nouns consist of a noun stem, preceded by a lexically defined noun class prefix, generally of the shape CV-. The noun class prefix (NPX) is preceded by a predictable pre-prefix or augment (AUG) vowel. In the remaining of the paper, augments are not separated from the noun class prefixes. The prefix vowels are subject to vowel harmony, e.g. Ikoma class 1 prefix is either omo- or omu- depending on the vowels of the nominal stem (Higgins 2012).

The prefixes for classes 5, 9, and 10 often deviate from the canonical form. In Ngoreme and Nata, the class 5 augment e- occurs only with monosyllabic noun stems. In Nata, the prefix vowel is also lengthened (rii-) (Anghelescu 2013: 90). In Isenye, the class 5 prefix occurs both with and without the augment.

In class 9, the shape of the prefix is VN- or V- as in Ikoma an-gibo 'cloth' and a-suná 'mosquito'. The vowels are a- in Ikoma and Nata, i-/e- in Isenye, e- in Ngoreme, and $\mathrm{N}$ is a homorganic nasal. In class 10 , the prefix is either $\operatorname{chVV}$ - or $\operatorname{chVVN}$, with the same vowels as in class 9 except that Ngoreme adds i- as an alternative of e-, as in Ikoma chaan-gibo 'cloths' and chaa-suná 'mosquitos'. 


\section{Syllable structure}

INI and Ngoreme conform to the typical Bantu syllable structure. The most common syllable type is the open syllable $\mathrm{CV}(\mathrm{V})$, where the vowels are of the same quality, i.e., constitute a long vowel. The consonant can be labialized or palatalized and/or prenasalized. Onsetless syllables are allowed word-initially. In Ikoma and Isenye a word-initial vowel is always short whereas initial long vowels are allowed in Nata and Ngoreme. In Ngoreme, adjacent vowels of different quality can occur, both morpheme internally, as in obu-náíní 'education', and across morpheme boundaries, but this is rather rare and the syllabic status of these vowel sequences is not clear.

Some restrictions apply to word-final syllables. None of the varieties allow word-final long vowels and in INI labialization or palatalization is not allowed in word-final syllables. While the typical Bantu patterns for passive and causative stems are -CVC-w-a and -CVC-ya, INI verbs with these extensions take the rather unusual shapes -CVC-u and -CVC-i, respectively. The same passive and causative endings are found in Ngoreme although elsewhere Ngoreme allows labialization and palatalization in word-final syllables.

In INI and Ngoreme, heavy syllables are those syllables that have long vowels. This definition is based solely on syllable weight and tone interaction: heavy syllables (CVV) attract $\mathrm{H}$ tones whereas light syllables $(\mathrm{CV})$ do not.

Long vowels in INI and Ngoreme are either lexical, a result of concatenation across morpheme boundaries, or a result of phonological condititioning that corresponds to compensatory lengthening in related Bantu languages. One environment where this "compensatory lengthening" takes place is after palatalization and labialization. Word-medial high vowels that follow consonants are glided and therefore lose the ability to bear tones; thus, to compensate for the loss of a vocalic segment, the following vowel is lengthened 
(Hyman 1985: 80). Lengthening also takes place word-medially before prenasalized consonants, where there is no vowel length opposition but the vowel is always long. Phonetically, compensatorily lengthened vowels fall between short vowels and long vowels (Higgins 2012); nevertheless, they are always considered long for purposes of tone rules. Note that since long vowels formed at morpheme boundaries are treated as long by the tone rules, the tone rules are applied at the surface level after segmental rules.

Although Bantu languages are typically described as having only open syllables, the segmental status of the prenasalized consonant is problematic, i.e., it is not clear if the nasal and the following consonant form a phonemic unit or if they are a sequence of discrete phonemes. Downing (2005) argues that the nasal can indeed be analyzed as a segment of its own and therefore it can form the coda of the preceding syllable. This analysis has been adopted by, for example, Ström (2013) for the Tanzanian Bantu language Ndengeleko. Ikoma tone placement with the first person singular object marker $\mathbf{n}$ - could be another piece of evidence supporting the sequence analysis (Aunio 2013: 289). When a Melodic H (MH) i.e., a $\mathrm{H}$ tone determined by the inflectional form of the verb - is assigned to the first syllable of the macrostem the $\mathrm{H}$ tone is realized on the object marker, which is usually of the shape $\mathrm{CV}$ (6). However, with the first person singular object marker which is only a nasal n-, the $\mathrm{H}$ tone is realized on the vowel of the preceding syllable, e.g., on the TAM marker (7). With this analysis the definition of heavy syllables in INI and Ngoreme conforms to syllable weight hierarchy: whenever a CVC syllable, $\mathrm{CVN}$ in this case, is considered heavy by the language, it also considers CVV syllables as heavy (Hyman 1985, Gordon 2004).

(6) Ikoma

mora[móboorera mo-ra-mo-boor-er-a

2.PL.SM-PRG-1.OM-tell-APPL-FV 'you told him/her'
(7) Ikoma

\section{moráá[mboorera mo-ra-n-boor-er-a}

2.PL.SM-PRG-1.SG.OM-tell-APPL-FV 'you told me' 
In Ngoreme, vowels are also lengthened before the alveolar trill $\mathbf{r}$, and these syllables behave as heavy for tonal rules. The trill is a result of the deletion of the vowel occurring between two alveolar flaps (r). This has happened morpheme-internally, e.g., Ngoreme ri-háára 'grasshopper', cf. eri-hárárá in Ikoma; but it also takes place synchronically across morpheme boundaries when an $\mathbf{f}$-ending verb stem adds either the Applicative suffix -er or the Perfective suffix -ire. For example, Ngoreme kw-erekééri 'to show' is kw-érekereri in Ikoma.

\section{Tone}

INI and Ngoreme have two level tones. These tones are treated as an opposition between $\mathrm{H}$ (indicated by an acute accent, e.g., á) and Ø (toneless, left unmarked in the examples), since only the $\mathrm{H}$ tones are active in the tone rules. Low tone is assigned as a default tone to any syllable that is not associated with a $\mathrm{H}$ after the tone rules (Aunio 2010; 2013). Although INI and Ngoreme have preserved the vowel length contrast, the Tone Bearing Unit (TBU) is the syllable. The tone is normally carried by a vowel, although in fast speech a vowel following a nasal is sometimes omitted and the $\mathrm{H}$ tone of the vowel is realized on the nasal.

There is usually only one $\mathrm{H}$ tone per word, with the exception of some MHs. Tones can be linked to more than one TBU, but one TBU can only have one tone linked to it. In INI the location of these tones is either defined in the lexicon (nominal tones) or predictable by the inflectional form (verbal tones or "Melodic Highs" (MHs), i.e., stem-tone alternations in verbal inflection (Odden \& Bickmore 2014)). In Ngoreme all tones are predictable either from the syllable structure or, in case of inflected verbs, the inflectional form.

While languages with this kind of restricted tonal systems are sometimes called pitchaccent languages, this paper adopts the view that pitch-accent is not a proper typological 
category, and that these languages combine both tone- and stress-like features (see Odden 1999, Hyman 2009). For example, these languages mostly satisfy the stress-related principle of obligatoriness, having at least one syllable with the highest prominence in a word. In these languages, the syllable with the highest prominence is the syllable with the $\mathrm{H}$ tone. On the other hand, the criteria used in assigning the $\mathrm{H}$ tones are often lexical or morphological, and therefore not directly related to the metrical structure of the word.

Odden (1999) states that weight-related tone placement is cross-linguistically not common, but in fact it is widely attested, for example, in the Chadic language family (Newman 1972). In Bantu, H tone retraction to a heavy penultimate syllable is found in several languages, for example Kimatuumbi (Odden 1996: 175-177) and Yao (Odden 1998: 295). Similarly in Kuria, heavy syllables with long vowels attract $\mathrm{H}$ tone spread (Odden 1987: 320). In INI the tone retraction to heavy syllables also applies to syllables other than the penult, and in Ngoreme the lexical tone placement is completely determined on the basis of syllable weight. In the following, the interaction between syllable structure and tone is described for Ngoreme and for each of the three varieties included in INI.

\section{Ikoma}

The Ikoma tonal system is fairly typical for Eastern Bantu languages. Ikoma, like all the other JE40 Mara Bantu languages, has lost the lexical tonal contrast of verb roots reconstructed for Proto-Bantu. Lexical tonal contrast is still active in some other Bantu languages of the area, for example in JE20 languages such as Jita (Downing 1996), some JE30 languages such as Tachoni (Odden 2009), and even in some JE40 languages spoken in Kenya, such as Gusii (JE42) (Nash 2011)) and Tiriki (JE423) (Marlo 2013)). Ikoma nouns have distinctive lexical tones (Aunio 2013; Aunio 2010). While verb roots do not have a lexical tone contrast, Ikoma 
makes use of "Melodic Highs" (MHs). It is only these MHs that are sensitive to syllable weight.

Ikoma assigns MHs to 4 positions in the verb: (a) the first syllable of the macrostem (8); (b) the second syllable of the macrostem (9); (c) the final vowel of the verb (10); and (d) the initial syllable (the subject marker) of the verb (11). Ikoma also allows toneless verb forms (12). The types of MHs that are sensitive to syllable weight are (b) tones assigned to the second syllable of the macrostem and (c) tones assigned to the final vowel. In the following examples, the surface tones are marked with the acute accent and the vowels of the target syllables of the MHs are underlined.
(8) mbaaku[ráágera
(9) ba[motómere
n-ba-Vko-raager-a
ba-mo-tom- $\varepsilon r-e$
FOC-2.SM-NPST-eat-FV
2.SM-1.OM-send-APPL-SBJV
'they eat/will eat'
'let them send her/him'
(10) mbaanga[raagiiré
(11) egesúsu gétoorera nyina...
n-ba-nga-raager-iri
eke-súsu ke-toor-er-a
nyina
FOC-2.SM-COND-eat-PFV
7-hare
7.SM-put-APPL-FV
mother
'they would eat'
'Having put [food] for his mother the hare...'
(12) mba[raagiire
n-ba-raager-iri
FOC-2.SM-eat-PFV
'they have eaten'

\subsection{H on the 2nd syllable of the macrostem}

The Subjunctive is the only form in Ikoma in which the MH is assigned to the second syllable of the macrostem. The same assignment pattern of the subjunctive tone can be found in several other Bantu languages, e.g., Tachoni (Odden 2009) and Ha (Harjula 2004). Ikoma also allows word-final $\mathrm{H}$ tones, and therefore the $\mathrm{MH}$ is also on the second syllable of the 
macrostem when the macrostem has only two syllables (13). The Subjunctive is formed with the final vowel -e, which causes vowel quality changes in some stem vowels (see, e.g., example 14 below).

\section{(13) a[remé \\ a-rem-e \\ 1.SM-cultivate-SBJV \\ 'let him/her cultivate'}

When the first syllable of the macrostem is heavy, i.e., has a long vowel, the $\mathrm{MH}$ is retracted from the second syllable to the first syllable, as in (14). This retraction also happens when the long vowel is due to(?) compensatory lengthening, as in examples (15)-(16). However, the heavy syllable has to be within the macrostem. The retraction does not take place if the heavy syllable is formed with the subject marker and a vowel-initial stem, as in (17) and (18). Nevertheless, the syllable which is formed with the subject marker and the initial vowel of the stem is counted when assigning the $\mathrm{MH}$, i.e., in bi[ishéreri 'let them agree' the $\mathrm{H}$ tone is on syllable she and not the following syllable re (which is the second "full" syllable of the macrostem). When the long vowel is formed with the object marker and the vowel-initial stem, it becomes the target of the retraction (19). An exception to this is the nasal only first person singular object marker, which seems to function as the coda of the previous syllable. That syllable counts as the first syllable of the macrostem but it does not attract the $\mathrm{H}$ tone since it is between the prefixes and the macrostem (20).

(14) tu[rééte

tu-rect-e

1.PL.SM-bring-SBJV

'let us bring'

(15) to[kúúndekeri

to-kuundekeri

1.PL.SM-cover.SBJV

'let us cover' mu[baréétere

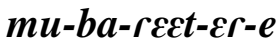

2.PL.SM-2.OM-bring-APPL-SBJV

'bring (you pl.) them'

(16) o[kwiíre

o-kwiir-e

2.SG.SM-marry-SBJV

'marry (you SG)' 
(17) bi[ishéreri

ba-ishereri

2.SM-agree.SBJV

'let them agree'

(19) ba[biite

ba-ba-it-e

2.SM-2.SM-kill-SBJV

'let them kill them'
(18) bi[ité

ba-it-e

2.SM-kill-SBJV

'let them kill'

(20) moo[ntúgeke

mo-n-tugek-e

2.PL.SM-1.SG.OM-make_sit-SBJV

'make (you pl.) me sit'

\section{2. $\mathrm{H}$ on the final syllable}

A MH is assigned to the final syllable in several verb forms in Ikoma, but there is variation in how the MH is realized between the different forms. Final MH can also occur in the same verb with other $\mathrm{H}$ tones. The target vowel of the $\mathrm{MH}$ is either the final vowel -a or the second vowel of the Perfective suffix -iri.

The MH docks onto the -iri suffix in both the Negative Anterior (ta- -iri) and the Conditional (nga- -iri) forms. In the Negative Anterior the $\mathrm{H}$ is always on the final syllable (21), while in the Conditional, the MH is optionally retracted to the penultimate syllable (22). Note that the retraction of the final $\mathrm{H}$ in the Conditional is not limited to heavy penultimate syllables (23), whereas in the Past (see below), the retraction only takes place when the penultimate syllable is heavy.

(21) ta[raagiiré

a-ta-raager-iri

1.SM-NEG-eat-PFV

's/he has not eaten'
(22) mbaanga[raagiiré $\sim$ mbaanga[raagíír n-ba-nga-raager-iri FOC-2.SM-COND-eat-PFV 'they would eat'

(23) neenga[torirí neenga[toríri

n-ne-nga-tor-iri

FOC-1.SG.SM-COND-be_able-PFV

'I would be able to' 
In the Past (a- -iri), there are two MHs: a MH assigned to the first syllable of the macrostem and a MH assigned to the last syllable (24). However, if there are less than four syllables in the macrostem, only the first $\mathrm{MH}$ is realized (25). This is because in bisyllabic macrostems the two MHs fall on adjacent syllables, and the latter is deleted by the well-known Meeussen's rule (Yip 2002: 100). A MH on the first and last syllable of the macrostem in trisyllabic stems results in a word-final $\mathrm{H} \emptyset \mathrm{H}$ sequence which is not allowed in Ikoma (Aunio 2013), and the final $\mathrm{H}$ is again not realized (26).

(24) naa[réremirí

n-a-a-re-rem-iri

FOC-1.SM-PST-5.OM-cultivate-PFV

's/he cultivated it (e.g. the field)'
(25) nee[róóche

n-ne-a-rooche

FOC-1.SM-PST-see.PFV

'I saw'

(26) naa[rémiri

n-a-a-rem-iri

FOC-1.SM-PST-cultivate-PFV

's/he cultivated'

The final $\mathrm{H}$ of the Past is always retracted to the penultimate syllable if that syllable is heavy (27) - (29). This is different from the Conditional in which the retraction is optional and happens even with light penultimate syllables (see (23) above), and from the Negative Anterior in which there is never $\mathrm{H}$ tone retraction (see (21) above). The long penultimate vowel in the Past is a result of the combination of the Applicative extension - $\mathbf{\varepsilon r -}$ and the -iri suffix.

(27) mbaa[kúúndekíiri n-ba-a-kuundekeri-iri

FOC-2.SM-PST-cover-PFV

'they covered'
(28) mbaa[yéékuundekír í n-ba-a-ye-kuundekeri-iri FOC-2.SM-PST-9.OM-cover-PFV 'they covered it' 
(29) mbaa[múherekeriíre

n-ba-a-mo-herekerer-iri

FOC-2.SM-PST-1.OM-accompany-PFV

'they accompanied her/him'

In the Narrative (Vka- -a) and the Inceptive (Vká- -a), the MH is also assigned to the final syllable and always retracted to the penultimate syllable when that syllable has a long vowel as in examples (30) - (34). However, these forms differ from the Past in that the $\mathrm{MH}$ is not realized at all if the penultimate syllable is not heavy, regardless of the number of syllables and the weight of the other syllables in the macrostem, as seen in examples (35) - (38) for the Narrative and examples (39) - (43) for the Inceptive. It should also be noted that while the long vowel is created across morpheme boundaries in the Past (e.g., example 29 above), in the Narrative and the Inceptive the penultimate long vowel is lexical.

(30) baaga[chetóóra ba-Vka-che-toor-a

2.SM-NAR-7.OM-put-FV

'and they put it'

(32) baaka[bóóka ba-Vka-book-a

2.SM-NAR-wake_up-FV

'and they woke up'

(34) baaká[mobóóki

ba-Vká-mo-book-i

2.SM-INC-1.OM-wake_up-CAUS

'they have woken the child up'

(35) baaga[chetora

ba-Vka-che-tor-a

2.SM-NAR-7.OM-pierce-FV

'and they pierced it'
(31) baaka[moshóómi ba-Vka-mo-shoomi

2.SM-NAR-1.OM-Spy_on

'and they spied on her/him'

(33) baaká[moshóómi

ba-Vká-mo-shoomi

2.SM-INC-1.OM-spy_on

'they begun to spy on her/him'
(36) aka[motukeri a-Vka-mo-tuk- $\varepsilon r-i$

1.SM-NAR-1.OM-dig-APPL-CAUS

'and s/he buried her/him' 
(37) baaka[raagera

ba-Vka-raager-a

2.SM-NAR-eat-FV

'and they ate'

(39) baaká[buga

ba-Vká-bug-a

2.SM-INC-say-FV

'they have said'

(41) baaká[raagera

ba-Vká-raager-a

2.SM-INC-eat-FV

'they began to eat'
(38) baaka[muraageri

ba-Vka-mo-raager-i

2.SM-NAR-1.OM-eat-CAUS

'and they fed her/him'

(40) baagá[karara

ba-Vká-karar-a

2.SM-INC-get_angry-FV

'they have got angry'

(42) baakáá[mboorera

ba-Vká-n-boorer-a

2.SM-INC-1.SG.OM-tell_sb-FV

'they have told me'

(43) baaká[herekerera

ba-Vká-herekerer-a

2.SM-INC-accompany-FV

'they have accompanied (her/him)'

Again, the syllables with long vowels caused both by gliding as well as prenasalization are considered heavy in the Narrative and the Inceptive, as in (44) - (45). Since the Inceptive formative (Vká-) has a H tone, the MH is deleted by Meeussen's rule if it is assigned to the first syllable of the macrostem, as in (46). As in the Subjunctive forms (see (17) - (20) above), only the long vowels formed within the macrostem are considered long and can be the target of the retraction, and therefore the syllable between the subject marker and the vowel-initial stem does not attract the $\mathrm{MH}$, as in example (47). Nevertheless, the $\mathrm{MH}$ is realized if the long vowel is derived within the macrostem, i.e., at the morpheme boundary between the object marker and the vowel-initial stem (48).

(44) baaka[byééma ba-Vka-byeem-a

2.SM-NAR-hunt-FV

'and they hunted'
(45) baaka[néénda ba-Vka-neend-a

2.SM-NAR-protect-FV

'and they protected' 
(46) baagá[seema

ba-Vká-seem-a

2.SM-INC-begin-FV

'they have begun'

(48) baaka[biíta

ba-Vka-ba-it-a

2.SM-NAR-2.OM-kill-FV

'and they killed them'
(47) baagi[ita

ba-Vka-it-a

2.SM-NAR-kill-FV

'and they killed'

As seen above, in Ikoma heavy syllables attract two types of MHs: those assigned to the second syllable of the macrostem and those assigned to the final syllable of the macrostem. The retraction rules of the final $\mathrm{H}$ are different between different verb forms: in some forms the retraction is optional while it is compulsory in others, and in some forms the final $\mathrm{H}$ is not retracted at all. The most interesting type of retraction takes place in the Narrative and the Inceptive in which the MH is not realized at all when the penultimate syllable is not heavy. This type of retraction is not found in the neighboring Bantu varieties, and it is possibly unique for Ikoma. Isenye shares some of the features seen in Ikoma, but also has some features not found in Ikoma.

\section{Isenye}

Like many other JE40 languages in the area, Isenye has no lexical tone of verbs but makes use of MHs in verbal inflection. Syllable weight plays a role in assigning the MHs, but the assignment rules are partly different from Ikoma. Also, Isenye's nominal tone system is greatly reduced from that of Ikoma (Aunio 2015). Whereas in Ikoma the tonal system is rather clear and stable, in Isenye there is a lot of tonal variation even in the speech of the same speaker; this variation might implicate that the Isenye tonal system is undergoing changes. 
As in Ikoma, the MH of the Subjunctive (-e) is assigned to the second syllable of the macrostem and retracted to the first syllable if it is a heavy syllable (49)-(51). Contrary to Ikoma where MHs do not spread, Isenye has the MH spread to both syllables of the macrostem in bisyllabic stems without heavy syllables (52).

(49)

\section{no[mugórere \\ n-o-mu-gór-er-e}

FOC-2.SG.SM-1.OM-buy-APPL-SBJV

'Buy (you SG) for them!'

(51) mo[géénde

mo-géénd-e

2.SM-go-SBJV

'Go (you PL)!'
(50) ba[ráágịre

ba-raagir-e

2.SM-eat-SBJV

'Let them eat!'

(52) mo[gúré

mo-gur-e

2.SM-buy-SBJV

'Buy (you PL)!'

Whreas in Ikoma the MH assigned to the second syllable of the macrostem is only found in the Subjunctive, this pattern is also found in the Past (a- -ire) in Isenye, as in examples (53) and (54). The retraction to heavy macrostem-initial syllable also applies in the Past, again both with contrastive (55) and conditioned long vowels (56).

m-ba-a-tuk-ire

FOC-2.SM-PST-dig-PFV

'they dug'

(55) mbaa[ráágẹre

m-ba-a-ráágir-ire

FOC-2.SM-PST-eat-PFV

'they ate'
(54) mbaa[ritúkire

m-ba-a-ri-tuk-ire

FOC-2.SM-PST-5.OM-dig-PFV

'they dug it'

(56) mbaa[twééreki

m-ba-a-tu-ereki

FOC-2.SM-PST-1.PL.OM-show.PFV

'they showed us'

Another Isenye form in which syllable weight plays a role is the Narrative (ka- -a) in which the $\mathrm{MH}$ is assigned to the third syllable of the macrostem, as in (57) and (58). While counting to three (and four) is attested in assigning tones in mora-counting language, such as the closely related Simbiti and Kuria, counting syllables to three is rare (Aunio et al. n.d.; Marlo, Mwita \& Paster 2014). However, counting syllables to three is also found in Nata nominal 
tone systems (see below). If the MH of the Narrative falls on the final syllable it is retracted to the penultimate syllable, as in (59) and (60). In bisyllabic and monosyllabic macrostems the $\mathrm{MH}$ is not realized at all, as in (61) and (62).

(57) gega[tomeráni

ke-ka-tomerani

7.SM-NAR-saw_together

'and it sewed together'

(59) kega[garúk

ke-ka-garuk-a

7.SM-NAR-return-FV

'and it returned'

(61) baka[buga

ba-ka-bug-a

2.SM-NAR-Say-FV

'and they said'
(58) geka[betomérani

ke-ka-be-tomerani

7.SM-NAR-8.OM-saw_together

'and it sewed them together'

(60) eka[mubóna

e-ka-mu-bon-a

9.SM-NAR-1.OM-See-FV

'and it saw her/him'

(62) eka[he

e-ka-he

9.SM-NAR-burn

'and it burned'

Macrostems with heavy syllables show retraction, but again a different type of retraction from that seen in Ikoma: whereas in Ikoma the retraction is always only to the adjacent syllable, this retraction takes place even if the heavy syllable is not adjacent to the original target syllable of the $\mathrm{MH}$.

(63) baka[tobóórera

ba-ka-to-boorer-a

2.SM-NAR-1.PL.OM-tell_sb-FV

'and they told us'

(65) gega[kúúndekeri

ke-ka-kuundekeri

7.SM-NAR-cover

'and it covered'
(64) gega[yekúúndekeri

ke-ka-ye-kuundekeri

7.SM-NAR-9.OM-cover

'and it covered it'

(66) geka[ráágeri

ke-ka-raageri

7.SM-NAR-feed

'and it fed'

As Isenye's tonal system has not been thoroughly analyzed only some features are presented here. Nevertheless, these already show that Isenye melodic tone assignment rules and heavy 
tone retraction rules are different from Ikoma. Nata, the third closely related variety, shows yet another type of the system.

\section{Nata}

Nata differs from Ikoma and Isenye in that Nata melodic tones are not sensitive to syllable weight and melodic tones are usually realized on the syllable which is the target syllable of the assignment rule (Lam in press). Whereas Ikoma and Isenye have syllable structure related rules for melodic tones, in Nata it is the nominal tone system that is partly sensitive to syllable weight. Anghelescu (2013) identifies three nominal tone types in Nata: (a) H tone assigned to the second syllable of the noun; (b) $\mathrm{H}$ tone assigned to the third syllable of the noun; and (c) H tone assigned to the final syllable of the noun. Of these, only the first pattern is affected by syllable weight. For a more comprehensive account of the Nata nominal tone system, see Anghelescu (2013), and see (Aunio 2015) for a comparative account of IkomaNata-Isenye nominal tone systems. It should be noted that a later analysis of Nata tones (Anghelescu et al. in press) proposes a different approach to Nata nominal tones: instead of counting syllables from the left edge of the word, $\mathrm{H}$ tones are assigned in relation to the macrostem, which includes the nominal prefix but not the augment. Nevertheless, the earlier approach is adopted here since it can also account for the similar phenomena in the closely related varieties.

When the noun class prefix - together with the augment - has the canonical VCV shape, the second syllable of the noun is the prefix syllable, and tone is therefore realized on the prefix syllable in Nata nominal tone type (a), as in the examples in (67). In class 9, in which the noun class prefix is $\mathbf{a}(\mathbf{N})-$, the $\mathrm{H}$ tone is realized on the first syllable of the nominal stem (68).

omó-remi 'farmer' abá-remi 'farmers' 


\begin{tabular}{|c|c|c|}
\hline egé-gi & 'wasp' & $\begin{array}{l}\text { ebé-gi } \\
\text { amá-gano }\end{array}$ \\
\hline
\end{tabular}

$\begin{array}{lll}\text { (68) } & \text { an-gíbo } & \text { 'cloth' } \\ \text { an-chéra } & \text { 'path' } \\ \text { a-búgusi } & \text { 'upper arm' }\end{array}$

The $\mathrm{H}$ tone of the second syllable of the noun is retracted to the initial syllable if the initial syllable is heavy (Anghelescu 2013). This happens in class 10, where the shape of the prefix is chaan- or chaa-, as in (69), and in class 5, where the prefix is rii-, as in (70).

$\begin{array}{llll}\text { (69) cháán-gibo } & \text { 'clothes' } & \text { cháá-bugusi } & \text { 'upper arms' } \\ \text { cháán-da } & \text { 'stomachs' } & \\ \text { (70) rí́-gano } & \text { 'story' } & \end{array}$

Monosyllabic nouns in class 9 form an interesting exception. With these nouns the prefix vowel in lengthened, both with type (a) nouns, as in (71), as well as with nouns in which the tone is assigned to the last syllable of the stem (type c), as in (72) (Anghelescu 2013).

$\begin{array}{lllll}\text { (71) áán-da } & \text { 'stomach' } & & \\ \text { (72) } & \text { aan-dá } & \text { 'louse' } & \text { aa-ká } & \text { 'house' }\end{array}$

The Nata verbal system does not show interaction between syllable weight and tone, but syllable weight is the determining factor for type (a) nominal tone. In Ngoreme, syllable weight plays a role in all lexical tone assignment.

\section{Ngoreme}

In Ngoreme, contrastive lexical tone on both verbs and nouns is lost, and there is only one melodic tone pattern, which assigns $\mathrm{H}$ to the first syllable of the verb stem. However, the Ngoreme system is not that of regular stress either. In inflected verbs, there is a $\mathrm{H}$ tone either on the TAM markers or on the first syllable of the stem, i.e. one syllable with the highest prominence is required for each word, but the place of this prominence is morphologically 
determined. On the other hand, in infinitive verbs as well as in nouns, the location of the highest prominence is determined by the syllable structure.

While the data presented in this article show only conditioned tones, it is possible that some varieties of Ngoreme have a more elaborate tonal system. For example, in the speech of some speakers, there appear to be three contrastive lexical tone patterns for bisyllabic noun stems. This variation requires further research.

Trisyllabic verb stems in the Infinitive clearly show the conditioning patterns. There are three tonal patterns, $\mathrm{H} \varnothing \varnothing, \varnothing \mathrm{H} \varnothing$, and $\varnothing \varnothing \mathrm{H}$, which are conditioned by the syllable structure of the stem. If the first syllable of the stem, as in (73), or the second syllable of the stem, as in (74), is heavy, the $\mathrm{H}$ tone is realized on the heavy syllable. As in all other tone assignment rules in Ngoreme as well as INI, the conditioned long vowels are also regarded as heavy. In case both the first and the second syllables are heavy, it is the second syllable that has the $\mathrm{H}$ tone, as in (75). When there are no heavy syllables in the verb stem the final syllable has the $\mathrm{H}$ tone (76). In stems without a heavy syllable, the $\mathrm{H}$ can also spread to the penultimate syllable or to the whole stem; this appears to be free variation. With vowel-initial stems the $\mathrm{H}$ is on the last syllable unless the second syllable is heavy, as in (77).

\begin{tabular}{|c|c|c|c|}
\hline ku-ráágera & 'to eat' & ko-híingira & 'to push' \\
\hline ku-hعhééna & 'to pant' & ko-mimiínta & 'to suck' \\
\hline gu-saasááma & 'to pray' & ku-baa & 'to squeeze' \\
\hline u-scboká & 'to sprout' & ko-higamá & 'to knee \\
\hline gw-ikará & 'to sit' & kw-ihíínya & 'to bow' \\
\hline
\end{tabular}

Quadrisyllabic consonant-initial verb stems have only two tonal patterns: HØØØ and ØНØØ. Stems without heavy syllables have the $\mathrm{H}$ tone on the stem-initial syllable, as in (78). $\mathrm{H}$ is also assigned to the first stem syllable if that syllable is the only heavy syllable of the stem, as in (79). $\mathrm{H}$ is on the second syllable of the stem in all other stems, i.e. when 1) the second 
syllable is the only heavy syllable of the stem (80);2) both the first and the second syllable are heavy (81); and 3) when the third syllable is heavy (82).

$$
\begin{array}{ll}
\text { ku-bérekera } & \text { 'to call' } \\
\text { ku-béćchegera } & \text { 'to ruminate' }
\end{array}
$$

gu-chabááchori 'to peel (away from oneself)' ko-biríngiti 'to roll'
ku-hoวyéćrana
'to copulate'
gu-saambáároka 'to rejoice'

Most of the vowel-initial quadrisyllabic verb stems have the $\varnothing \mathrm{H} \varnothing \varnothing$ pattern: the initial stemsyllable which is shared with the infinitive prefix never carries the $\mathrm{H}$ tone, as in (83).

However, there are some stems in which the penult is heavy and the $\mathrm{H}$ tone is realized on the penult (84), or on both the second syllable and the penult (85). In all of these, the verb has - $\mathbf{\varepsilon \varepsilon r}$ or - $\mathbf{\varepsilon \varepsilon r}$ before the final vowel. While - $\mathbf{\varepsilon \varepsilon r}$ is part of the stem, the alveolar trill in - $\mathbf{\varepsilon \varepsilon r}$ is a result of vowel deletion. Extended stems with any other long vowel do not shift the tone (86).

\begin{tabular}{|c|c|c|c|}
\hline gw-EEsémora & 'to sneeze' & gw-iichóógani & 'to mix' \\
\hline kw-oorwéécheru & 'to be engaged & ' kw-iináánseعra & 'to coil' \\
\hline kw-aangohééri & 'to hurry' & kw-eerekééri & 'to show' \\
\hline gw-iitégéćca & 'to think' & gw-iitábééri & 'to agree' \\
\hline gw-iitóroวra & 'to pour' & & \\
\hline
\end{tabular}

Since Ngoreme requires at least one syllable with the highest prominence in a word the monosyllabic verb stems all have a $\mathrm{H}$ tone in the Infinitive, as in (87). Bisyllabic verb stems have two tonal patterns, again distributed according to the syllable structure of the verb stem: the stems without heavy syllables have the $\mathrm{H}$ on the first syllable of the stem (88), whereas when the first syllable of the stem is heavy, the heavy syllable has a rising tone which is also extended to the final syllable (89).

$\begin{array}{lllll}\text { (87) } & \text { go[tú } & \text { 'to pick' } & \text { ko[nyó } & \text { 'to drink' } \\ (88) & \text { ko[rúga } & \text { 'to cook' } & \text { gu[tóma } & \text { 'to send' }\end{array}$


ku[gećndá 'to walk' $\quad$ ku[bośká ～'to wake up'

Ngoreme is an intriguing language since it shares a lot of features of both South Mara (e.g.

INI) and North Mara (e.g. Kuria and Simbiti) languages. The Ngoreme tonal system resembles South Mara languages with, for example, the syllable as the TBU and weight sensitive tonal distribution. However, Ngoreme differs from INI in the way syllable weight affects tonal realizations.

\section{Conclusion}

Although Ikoma-Nata-Isenye (INI) and Ngoreme are geographically and socially close to one other they show a lot of variation in their prosodic systems. Ngoreme stands out as having no distinctive tone, neither lexically nor grammatically, and syllable weight plays a role only in assigning lexical tones while grammatical tones are morphologically determined. IkomaNata-Isenye, although coded as dialects of the same language, also show a high degree of internal difference in the prosodic systems. Ikoma and Isenye are similar in that they have a melodic tone system that is affected by syllable weight, but nominal tones are lexically assigned. Nata, on the other hand, has lexically defined nominal tones that are sensitive to syllable weight, whereas Nata melodic tones are not.

\begin{tabular}{|l|l|l|l|l|}
\hline & Ikoma & Nata & Isenye & Ngoreme \\
\hline Contrastive nominal tone & yes & yes & yes & no \\
\hline Contrastive verbal (melodic) & yes & yes & yes & no \\
\hline Nominal tones sensitive to & no & yes & no & yes \\
syllable weight & & & & \\
\hline
\end{tabular}




\begin{tabular}{|l|l|l|l|l|}
\hline Verbal (melodic) tones sensitive & yes & no & yes & no \\
to syllable weight & & & & \\
\hline
\end{tabular}

Table 1. Comparing INI and Ngoreme prosodic systems

Although Ikoma and Isenye are the most similar of the four varieties discussed here there are interesting differences also between them when it comes to tone and syllable structure. For example, in Ikoma $\mathrm{H}$ heavy syllable retraction of melodic tones operates only between adjacent syllables, whereas in Isenye more long distance retraction is possible. Furthermore, Ikoma counts only up to the second syllable from the edges of the macrostem, but Isenye has forms in which the $\mathrm{H}$ tone is assigned to the third syllable of the macrostem.

In the Ngoreme variety presented here, tones are always determined either morphologically or on the syllable structure. Moreover, on the word level, Ngoreme requires at least one syllable with the highest prominence. On the other hand, the Ngoreme system is not clearly a stress system since the culminativity principle is not always satisfied as the $\mathrm{H}$ tones can be realized on more than one adjacent syllable.

The internal differences in the tonal systems of INI suggest that these three varieties are not as closely related as has been previously thought. While the prosodic systems of Ikoma and Isenye are more similar to one another as opposed to the Nata system, it is interesting to note that Ikoma and Isenye are not geographically adjacent, since the Nata area is located between them.

Although the analysis presented here does not give direct answers to the history and development of the South Mara Bantu languages, it provides one piece to the puzzle. Moreover, this article provides a description and understanding of the tone-syllable structure interface in Eastern Bantu languages. Finally, it also contributes to prosodic typology not by placing these languages on the "stress-tone scale" but, as argued by Hyman (2009), but by 
describing in detail what properties typical of stress languages these languages make use of, and how these properties interact with tone.

\section{Abbreviations}

\begin{tabular}{ll|cl|cl} 
APPL & applicative & INC & Inceptive & OM & object marker \\
AUG & augment & INF & Infinitive & PFV & Perfective \\
C & consonant & INI & Ikoma-Nata-Isenye & PRG & Progressive \\
CAUS & Causative & MH & Melodic H & PST & Past \\
COND & Conditional & N & nasal & SBJV & Subjunctive \\
EXT & extension & NAR & Narrative & SG & singular \\
FOC & focus & NEG & negation & SM & subject marker \\
FV & final vowel/suffix & NPST & Non-Past & TAM & tense/aspect/mood \\
H & high tone & NPX & noun class prefix & V & vowel
\end{tabular}

Acknowledgements: I would like to thank all the speakers of Ikoma, Nata, Isenye, Ngoreme, and Simbiti with whom I had the pleasure working with during various field trips to the Mara region. I would also like to thank the Emil Aaltonen Foundation and the Finnish Cultural Foundation for making the field work possible, and SIL colleagues for fruitful cooperation.

\section{REFERENCES}

Anghelescu, Andrei 2013. Morphophonology and tone in Nata. UBC Working Papers in Linguistics 34: 89-103. 
Anghelescu, Andrei, Joash Gambarage, Zoe Lam \& Douglas Pulleyblank. in press. Nominal and verbal tone in Nata: An Allomorphy-based account.

Aunio, Lotta. 2010. Ikoma nominal tone. Africana Linguistica 16: 3-30.

Aunio, Lotta. 2013. Ikoma verbal tone. Nordic Journal of African Studies 22(4): 274-321.

Aunio, Lotta. 2015. A typological perspective on Bantu nominal tone: The case of IkomaNata-Isenye in western Tanzania. SALALS 33(3): 359-371, DOI:

10.2989/16073614.2015.1105106.

Aunio, Lotta, Holly Robinson, Timothy Roth, Oliver Stegen, and John B. Walker. forthcoming. The Mara languages (JE40). In The Bantu Languages, 2nd edn.

Downing, Laura J. 1996. The Tonal Phonology of Jita. Munich: Lincom Europa.

Downing, Laura J. 2005. On the ambiguous segmental status of nasals in homorganic NC sequences. In The Internal Organization of Phonological Segments, ed. by Marc van Oostendorp and Jeroen van de Weijer, pp. 183-216. Berlin: De Gruyter Mouton.

Gordon, Matthew. 2004. Syllable weight. In Phonetic Bases for Phonological Markedness, ed. by Bruce Hayes, Robert Kirchner, and Donca Steriade, pp. 277-312. Cambridge: Cambridge University Press.

Harjula, Lotta. 2004. The Ha Language of Tanzania: Grammar, Texts and Vocabulary. (East African Languages and Dialects, 13) Cologne: Rüdiger Köppe.

Higgins, Holly Ann. 2012. Ikoma Vowel Harmony: Phonetics and Phonology. Available at <http://www.sil.org/resources/publications/entry/51528>.

Hill, Dustin, Anna-Lena Lindfors, Louise Nagler, Mark Woodward, and Richard Yalonde. 2007. A sociolinguistic survey of the Bantu languages in Mara region, Tanzania. Unpublished ms., Dar es Salaam: SIL.

Hyman, Larry M. 1985. A Theory of Phonological Weight. (Publications in Language Sciences, 19) Dordrecht: Foris Publications.

Hyman, Larry M. 2003. Segmental phonology. In The Bantu Languages, ed. by Derek Nurse and Gérard Philippson, pp. 42-58. London: Routledge.

Hyman, Larry M. 2009. How (not) to do phonological typology: The case of pitch-accent. Language Sciences 31(2-3): 213-238.

Lam, Zoe Wai.-Man. in press. The verbal morphotonology of Nata. UBC Working Papers in Linguistics.

Maho, Jouni Filip. 2009. New Updated Guthie List. 2nd edition. Available online at <goto.glocalnet.net/mahopapers/nuglonline.pdf>.

Marlo, Michael R. 2013. Verb tone in Bantu languages: Micro-typological patterns and research methods. Africana Linguistica 19: 137-234. 
Marlo, Michael R., Leonard Chacha Mwita, and Mary Paster. 2014. Kuria tone melodies. Africana Linguistica 20: 277-294.

Muzale, Henry R. T., and Josephat M. Rugmalira. 2008. Researching and documenting the languages of Tanzania. Language Documentation and Conservation 2: 68-108.

Nash, Carlos M. 2011. Tone in Ekegusii: A Description of Nominal and Verbal Tonology. Ph.D. dissertation, University of California, Santa Barbara.

Newman, Paul. 1972. Syllable weight as a phonological variable. Studies in African Linguistics 3: 301-323.

Nurse, Derek. 1999. Towards a historical classification of East African Bantu languages. In Bantu Historical Linguistics: Theoretical and Empirical Perspectives, ed. by JeanMarie Hombert and Larry M. Hyman, pp. 1-35. Stanford: CSLI Publications.

Nurse, Derek. 2008. Tense and Aspect in Bantu. Oxford: Oxford University Press.

Odden, David. 1987. Predicting tone in Kikuria. In Current Approaches to African Linguistics, vol. 4, ed. by David Odden, pp. 311-326. Dordrecht: Foris Publications.

Odden, David. 1996. The Phonology and Morphology of Kimatuumbi. (The Phonology of the World's Languages) Oxford: Clarendon Press.

Odden, David. 1998. Principles of tone assignment in Tanzanian Yao. In Theoretical Aspects of Bantu Tone, ed. by Larry M. Hyman and Charles Kisseberth, pp. 265-314. Stanford: CSLI.

Odden, David. 1999. Typological issues in tone and stress in Bantu. In Proceedings of the Symposium Cross-Linguistic Studies of Tonal Phenomena, Tonogenesis, Typology, and Related Topics, ed. by Shigeki Kaji, pp. 187-215. Tokyo: ILCAA.

Odden, David. 2009. Tachoni verbal tonology. Language Sciences 31: 305-324.

Odden, David, and Lee Bickmore. 2014. Melodic tone in Bantu: Overview. Africana Linguistica 20: 3-14.

Pakendorf, Brigitte, Koen Bostoen, and Cesare de Filippo. 2011. Molecular perspectives on the Bantu Expansion: A Synthesis. Language Dynamics and Change 1(1): 50-88.

Roth, Tim. 2014. The case of Ngoreme: Distinguishing contact from genetic inheritance in Mara Bantu. Unpublished paper presented at the conference Language Contact: The State of the Art (Helsinki, August 28-30, 2014).

Shetler, Jan Bender. 2007. Imagining Serengeti: A History of Landscape Memory in Tanzania from Earliest Times to the Present. Athens, $\mathrm{OH}$ : Ohio University Press.

SIL. 2010. Ikoma Orthography Sketch: Final Edition. Musoma: SIL International, UgandaTanzania Branch. 
SIL. 2011. Ngoreme Orthography Sketch. Musoma: SIL International, Uganda-Tanzania Branch.

Ström, Eva-Marie. 2013. The Ndengeleko Language of Tanzania. Ph.D. dissertation, University of Gothenburg.

Walker, John B. 2013. Comparative Tense and Aspect in the Mara Bantu Languages: Towards a Linguistic History. M.A. thesis, Trinity Western University. Available at <http://www.canil.ca/programs/MA_LING/theses/Walker\%202013.pdf>.

Yip, Moira. 2002. Tone. Cambridge: Cambridge University Press. 